sole of the foot; part of the swelling was firm, part was elastic, as if containing fluid; the integuments covering it were thinned and livid, and had given way in one spot, exposing a fungous-looking mass of granulations: the movement in the joint was perfect. The limb was removed, and the morbid change was found to be limited to the synovial theca, which surround and accompany the tendons of the tibialis posticus and the flexor communus digitorum muscles to the sole of the foot. It was therefore strictly circumscribed and surrounded by healthy structures. The thecæ were thickened: their usual bright synovial surface was converted into a dull, uneven velvety structure, from which was produced a soft growth composed of cystoblasts, and a small quantity of delicate fibrous tissue. This growth made its way upwards between the posterior surface of the tibia and the tendo Achillis, and downwards into the sole of the foot, between the flexor brevis digitorum and the flexor accessorius muscles, both of which were quite healthy. The flexor tendons were unaltered in structure, but were surrounded by the soft growths above described, and by a large quantity of morbid synovial secretion, which seemed to be contained in more cavities than one; for behind the malleoli it was of pale straw colour, and somewhat stringy, whilst in the sole of the foot it was of watery consistence, of red colour from admixture of blood, and contained coagula.

I cannot conclude this paper without strongly recommending those who desire further information on the subject to consult the thesis of M. Michon, ${ }^{1}$ to which I am indebted for many of the preceding details.

\title{
ON THE INTRODUCTION OF SOLUTIONS OF LEAD INTO THE BLADDER, FOR THE DECOMPOSITION OF PHOSPHATIC CALCULI.
}

\author{
By S. ELLIOTT HOSKINS, M.D., F.R.S.
}

Is a paper which the Royal Society did me the honour of publishing, ${ }^{2}$ some account was given of the decomposition of Phosphatic Calculi, by solutions of certain salts of lead, so dilute as to admit of their reten. tion by the living bladder, without irritation or inconvenience.

The adaptation of the principle of double decomposition to the disintegration of vesical calculus, is in strict accordance with chemical usage : it supplies a class of agents, more energetic as regards the concretion, and less injurious to the organ in which it is contained, than any of the uncombined solvents hitherto employed. The solvent, no matter how dilute, can only be tolerated for a minute or two at

1 Des Tumeurs Synoviales de la Partie Infërieure de l'Avant-Bras, de liı Face Palmaire du Poignet et de la Main. Thèse présentée an concours pour ume Chaire de Clinique Chimurgicale. Par L. M. Michon. Paris : 1851.

? Philosophical Transactions, Part I, $1 \times 13$. 
farthest, and cannot soon be repeated : the decomponent, on the contrary, is retained from ten to fifty minutes without discomfort, and may be repeated daily, or oftener if necessary. The cause of this difference is sufficiently obvious : the active agent of the decomponent is liberated gradually, and neutralised by the earthy bases of the calculus, before it can come in contact with the living tissues; whereas the former class of fluids causes such immediate irritation, that their ejection is required before any impression can be made on the concretion. The base of the decomponent unites with the acid of the calculus, while the acids of the former combine, and form soluble salts, with the bases of the latter. The combined acids are set free in definite proportions, neutralised in their nascent state, and removed from the sphere of action before any stimulating effect can be exerted on the bladder.

The cases which I am about to bring forward, although sufficient to prove the unirritating effect of these decomponents, when thrown into the bladder, are by no means calculated to test the amount of their action on the very concretions which they decompose so energetically out of it. It is not, however, because I cannot cite a host of triumphant cases establishing both points, that the observations I have been enabled to make, as to the mild character of the solutions, ought to be withheld.

Case I. Mr. F., aged 72, a patient of Mr. Coulson, was affected with palsy of the bladder; the urine was occasionally alkaline, and charged with phosphatic deposit. He suffered much from the accumulation of ropy mucus; it often prevented the urine from flowing through the catheter, without the introduction of which the bladder was never evacuated. The instrument, when passing through the prostatal portion of the urethra, was felt to grate over a considerable extent of calcareous matter impacted in the gland. $\mathrm{He}$ had experienced mitigation of symptoms, as regarded the mucus, from the injection of very dilute nitric acid; but in consequence of the irritation it occasioned, he could not bear its repetition a third time. Nevertheless, a solution of lead was, from the first, retained for twenty minutes; it produced a soothing effect at the time, and was not followed by the slightest annoyance. It was continued daily, or every second day, for six weeks, and often retained for half an hour. On rejection the fluid appeared milky, contained flakes of coagulated mucus, and yielded a considerable precipitate of phosphate of lead. The eyes of the catheter often contained gritty particles enveloped in mucus, which yielded a sensation similar to that produced by rubbing the pineal gland between the fingers. At the end of the above-mentioned period, no grating sensation could be felt on passing the catheter; the injection was therefore discontinued for some months, but again resumed, in consequence of a recurrence of this sensation, and of the mucoid secretion. After being persevered in for some time, it was again left off, relief having been obtained.

CASE Ir. This gentleman was a patient of Mr. Guthrie. His general health had been very much impaired by long-continued suffering. Two calculi had been originally present in the bladder. One had been crushed, and the greater part of it removed; but the fragment retained was the cause of much uneasiness, especially when it rested 
on the neck of the bladder. The urine was alkaline and bloody, containing mucus, and apparently pus. A stricture also existed in the urethra. The bladder was very irritable, but bore the presence of the lead solution for twenty minutes, with no more inconvenience than that which resulted from the introduction of pure water. The injection was continued every second day for nearly a fortnight. Particles of calculus frequently came away some hours after its use; they consisted of oxalate of lime, cemented together by triple phosphate. The latter was rapidly acted upon by the lead solution. The patient died soon after. Both his kidneys were found to be diseased, containing pus; the right enclosed four calculi. One stone was found in the bladder, besides that which had been broken up by Mr. Guthrie. A very small portion of the latter remained.

CASE III. This was a patient of Mr. Key and Mr. Hunter. His bladder contained a large triple phosphate calculus. He had been lithotritised by another surgeon, unsuccessfully. The operation had caused much pain, and subsequent irritation, which had been soothed by injections of opium and warm water thrown into the bladder. The urine was neutral and turbid, containing blood and mucus. He occasionally passed calculi, of the size of small orange pips, which were readily decomposable by the lead solution. This fluid, when injected, was retained by the bladder without inconvenience, the first time for ten minutes, the second for half an hour, the third, fourth, and fifth, for fifty minutes. The rejected fluid deposited considerable quantities of precipitate on the filter. On one occasion it amounted, when dried, to eighteen grains of phosphate of lead.' Owing to some prejudice on the part of the patient, the injection was discontinued after the first week. This was unfortunate, as the case appeared to be favourable for testing the value of this mode of treatment.

Cuse IV. 'This was a patient of Mr. Copeland, aged 78, who had laboured for some time under vesical calculus, but on whom it was not expedient to operatc. He used the solution for three weeks before his death. It was productive of a soothing effect on the bladder; and, whenever it was used, the ensuing evacuation of urine deposited a number of small crystals, but at no other time were they passed. After death, two large calculi were found in the bladder, and a smaller one sheltered behind an enlarged prostate. The surface of the concretions was studded with crystals, of the same description as those which had been brought away during life by the injection.

CASE v. A retired army surgcon, aged 72 , had been lithotritised seven years before, after which he had passed many fragments of uric acid calculus, with phosphatic coating. The prostate was enlarged, and the constant use of the catheter required. He tried the solution of lead twice or thrice a day for about a fortnight; but, although the bladder was irritable, the liquid, as he stated to me, caused " no pain whatever; on the contrary, it acted as a sedative to the lining membrane". He had, however, made up his mind to lithotomy, which was performed by Mr. Keate, and a stone, composed of fusible matter, urate of ammonia, and oxalate of lime, removed. On immersing frag-

1 For this quantity of phosphate of leal, the equiralent is twelve grains of ammonio marke sian pho.phate. 
ments of this calculus in the solvent, he found that, "after a few hours, they had diminished one half in bulk and weight; the exterior coating being eaten away, and the nucleus appearing a very different substance, much darker and harder". About three months after the operation, he again felt uneasy sensations, as though another fragment existed. He continued the use of the lead injection, which he found very soothing.

CASE vi. Another patient of Mr. Coulson had long been suffering from affection of the urinary organs. He occasionally passed particles of calculous matter, but no stone could be detected in the bladder. This organ was paralysed, and required the constant introduction of the catheter for its evacuation. This gentleman was subject also to severe spasms, from the retention of a morbid secretion of vesical mucus, which, on bcing voided, was found to contain particles of phosphate of lime. He derived "much comfort" from the injection of the lead solution, and found that it lessened the secretion of mucus, facilitated its expulsion, and thereby lessened the frequency of painful calls to evacuate the bladder. There appeared to be also a greater disposition to expel the urine by natural efforts.

Other cases could be adduced, but the foregoing are sufficient to prove, not only that the bladder, under irritation, tolerates the presence of these solutions of lead, but also that they act as sedatives, and exert a favourable influence, directly and indirectly, on the morbid secretion of mucus which exists in cases of this nature.

After having made trial of most of the vegetable supersalts of lead, all of which act, more or less, as unirritating decomponents, I have returned to the use of that originally proposed, the nitro-saccharate, ${ }^{1}$ as by far the most effective. That prepared for me by Mr. Garden, of Oxford-street, is much more energetic as a chemical agent than my own, and equally mild in its physiological effects. It is likewise more decidedly an organic salt, which I consider essential to the fulfilment of the ends in view; and I am strengthened in the opinion that sugar is a necessary ingredient, from the perusal of two papers in the July number of the Pharmaceutical Journal; one by M. E. Peligot, On the Combinations of Sugar with Lime, and another by M. Barreswill, On the Solution of Carbonate of Lime in the Saccharates.

One grain of the salt, superacidulated with five drops of strong acetic acid, is the proper proportion for admixture with each fluid ounce of water. ${ }^{2}$ It is essential that the salt and the acid should be incorporated before the addition of the water, and that the whole should be brought to the boiling point. Superacidulation is necessary on many accounts; it secures perfect solution, increases the decomposing activity of the liquid, and prevents the formation of any carbonate of lead.

As the salts contained in the urine tend to decompose the solution, and lessen its effects on the concretion, the bladder should be eva-

1 Philosophical Transactions, 1843, p. 11.

2 The decomposing power of these solutions is in inverse ratio to their concentration; for instance, a satnrated solution of the acetate, superacidulated pretty freely, is inert; whereas, in the above proportions, decomposition of phosphatic calculi takes place rapidly. 
cuated, and washed out with tepid water before the lead fluid is introduced. A double-current caoutchouc catheter is the best for this purpose, as it enables a continuous stream to be employed; and as, on account of its flexibility, it is less liable to irritate the urethra, which should be sedulously avoided. From four to eight fluid ounces of the solution may be thrown into the bladder at a time, and renewed every ten or fifteen minutes, as often as may be deemed proper. By renewing the liquid at short intervals, much greater effect on the calculus is ensured, than when it is allowed to remain longer; for the precipitate formed by decomposition soon envelops the stone, and puts a stop to further action, until a fresh surface is exposed. Exercise during the retention of the injection increases its effect. Some slight revulsion may be produced by the first introduction of this, or any other fluid, into the bladder; when such is the case, the operation should be remitted for a day or two, and cautiously renewed. The injection may be either warm or cold, as may be most agreeable to the sensations of the patient. Warmth favours the decomposition of the calculus.

If used with proper precautions, I have found that the lead solutions exert as sedative and salutary an influence on the lining membrane of the bladder, as they do on external surfaces under inflammation. They also act upon the mucus, which is so abundantly formed in cases of this nature, coagulating it into short curdy flakes, which are easily passed through the urethra.

When the urethra itself is inflamed, or abraded, the injection will be injurious; for the lining membrane of the canal is, I believe, more sensitive than that of the bladder. The introduction therefore of decomponents should be had recourse to, either before lithotrity, or after the urethra has recovered from the effects of the instruments employed, but can never be used, with any prospect of success, where organic disease of the bladder or prostate exists. The injection should not be employed during the internal exhibition of hydrochloric acid, although it may be freely used when nitric acid is administered. When the bladder is not very irritable, a dilute nitric acid injection, alternating with the lead solution, will hasten decomposition.

The two facts established with respect to the lead salts, viz., first, their toleration by the bladder, and, sccondly, their chemical action on calculous concretions, induce me to hope that they may become useful agents in the treatment of various other affections of the urinary organs. I have never presumed to imagine they would prove specific solvents for the stone; but, 1 trust that, where surgical operation is inadmissible, they will be of some avail for relief, if not for cure, by smoothing asperities, and removing the outward phosphatic coating of calculi, so as to bring them within the verge of the crushing forceps; in short, that they may avail for partial, if not for entire disintegration. The latter is more likely to happen where layers, composed of the urates or oxalates, are bound together by phosphatic cement. On this species of calculus, they are calculated to act as highly carbonated waters do on those of another description.

"Nor is the action of highly carbonated waters", says Dr. Prout, "confined to their mere solvent effects; they undoubtedly possess disintegrating power; that is, the power of disturbing the attraction, 
both cohesive and adhesive, by which the molecules of the calculi are held together, so as to render them brittle and easily broken into fragments". This is an additional reason for using decomponents before recourse is had to lithotrity.

Besides the kind of cases already adduced, there is one variety for which decomponents secm to be peculiarly adapted; viz., concretions in the prostate gland. No instrument hitherto devised has been successful in dislodging them. The first case, however, mentioned in the present paper, goes to prove that a considerable quantity of calcareous matter was removed from the prostatal portion of the urethra, by the use of the lead injection.

In the first experiment communicated to the Royal Society, it was stated, that one hundred grains of calculus immersed in lead solution for forty minutes, had lost twelve grains. In the second experiment, the quantity dissolved, from a fragment weighing thirty-seven grains, was, after half an hour's immersion, eight grains. Subsequent experience has verified these observations, and proves that, under favourable circumstances, decomposition takes place in definite proportions; so that, from the precipitate of phosphate of lead, the quantity of ammonio-magnesian phosphate which has been decomposed may be securely estimated.

Since these circumstances obtain out of the bladder, by means of a fluid which can be borne by that organ with impunity, we may reasonably hope, that the mere transference of the scene of action, from the exterior to the interior, will not materially affect the results.

The foregoing communication contains the substance of a paper read before the Royal Medical and Chirurgical Society, the debate ${ }^{1}$ on which was founded chiefly on a solitary case, confessedly one of the most unfavourable that could have been selected; one in which " nothing could be injected into the bladder without producing great irritation." The consequence was a natural disinclination to give the lead solution further trial. This paper not being deemed worthy of publication, and the Philosophical Transactions not being read extensively by medical men, the subject has not hitherto been before the profession. Its present publication arises from fortuitous circumstances, and a conviction that there are certain conditions in which the means recommended are likely to be beneficial, rather than from any desire to assume peculiar merit, or from motives of personal interest. I am as far removed by local position, if by nothing more, from the influence of the one, as I am indifferent to the other.

Having ascertained that a certain solution, mild enough to be tolerated by the human bladder, ${ }^{2}$ exerts much chemical influence on phosphatic calculi, I am desirous of engaging the attention of those among my professional brethren, whose abilities and opportunities may enable them to pursue the investigation more thoroughly than I can.

Guernsey, Sept. 3, 1851.

1 Reported in the Lancet, June 2:, 184.4.

2 My own eye was the first test of its milduess. 